\title{
BMI and physical activity in Black Afro-Caribbean adults
}

\author{
D. L. Omisore and G. J. Davies \\ London South Bank University, London SE1 OAA, UK
}

Obesity has persisted as one of the country's top public health problems; it is rising in incidence particularly among Black AfroCaribbean's. It is suggested that increased obesity levels in Afro-Caribbean adults are not as a result of ethnic and genetic factors alone, but as a result of behaviours in which they may engage, environmental forces and a complex interaction between these factors ${ }^{(1)}$.

Afro Caribbean's constitute the second largest ethnic minority group in the United Kingdom and among whom there is a poor outcome for obesity and associated diseases ${ }^{(2)}$. Two thirds of Afro-Caribbean women are overweight or obese compared with around half in the general population, and this problem gets worse with age, with over ninety percent of Afro-Caribbean women overweight by the age of fifty five $e^{(3)}$.

The present study has investigated the relationship between BMI and physical activity levels in men and women. Eighty Caribbean subjects were recruited from a Pentecostal church congregation in London, UK. A cross sectional survey was conducted among male and female subjects; a self administered questionnaire was given to the subjects after a Sunday church service. The questionnaire was used to elicit information concerning self image, perceptions of obesity, dietary practices, food consumption and physical activity. Eighty subjects were administered the questionnaire, forty four completed the assessment process. Anthropometric data were taken for each subject: height; body weight; BMI. Physical activity was determined using the international physical activity questionnaire ${ }^{(4)}$.

\begin{tabular}{lll}
\hline & Men $(n$ 9) & Women $(n$ 35) \\
\hline Age (years) & & \\
$\quad$ Mean & 41 & 42 \\
$\quad$ Range & $27-62$ & $25-66$ \\
BMI $\left(\mathrm{kg} / \mathrm{m}^{2}\right)$ & & \\
$\quad$ Mean & 25.3 & 26.5 \\
$\quad$ Range & $20.1-29.6$ & $16.3-49.6$ \\
Physical activity level $(n)$ & & \\
$\quad$ Low & 2 & 19 \\
$\quad$ Moderate & 7 & 15 \\
$\quad$ High & 0 & 1 \\
\hline
\end{tabular}

The mean BMI in both groups was above the normal range. Furthermore, in females a high BMI was associated with low levels of physical activity. This trend was also noted in males, although the sample was small. Most of the physical levels in both genders were classified as low and moderate. Further work on BMI and physical activity in Afro-Caribbean adults is needed to build on these initial findings.

1. Mokdad AH, Dietz SM, Bowman BA, Marks JS \& Koplan JP (1999) JAMA 282, 1519-1522.

2. Chatters LM, Levin JS, Ellison CG (1998) Public health and health education in faith communities. Health Education Behaviour 25, 689-99.

3. National Task Force on the Prevention and Treatment of Obesity (1994) Towards prevention of obesity. Obesity Research 2, 571-584.

4. Craig CL, Marshall AL, Sjostrom M, Bauman AE, Booth ML, Ainsworth BE, Pratt M, Ekelund U, Yngve A, Sallis JF \& Oja P (2003) Med Sci Sports Exerc 35, 1381-1395. 